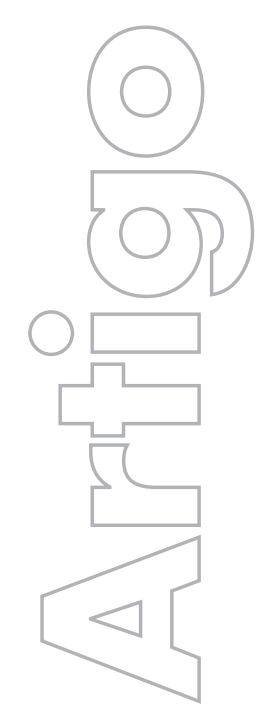

revista

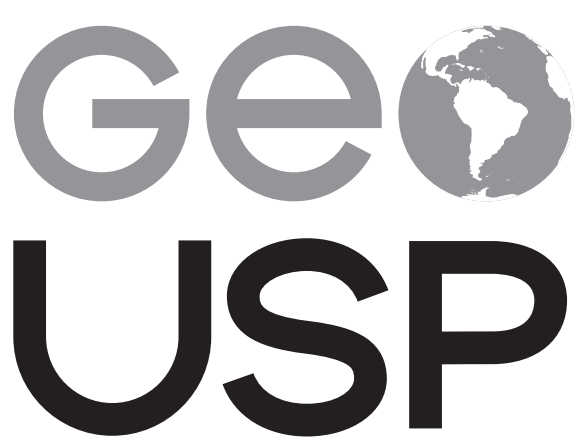

espaço e tempo

Volume $21 \cdot n^{\circ} 3(2017)$

ISSN 2179-0892

\section{A inserção do Brasil}

no sistema-Terra, na

totalidade-mundo e na

economia mundial, segundo

a geografia regional: de

Vidal de la Blache a Pierre

Monbeig (1911-1957)

Larissa Alves de Lira

USP/École des Hautes Études en Sciences Sociales

p. $793-811$

Como citar este artigo:

LIRA, L. A. A inserção do Brasil no sistema-Terra, na totalidade-mundo e na economia mundial, segundo a geografia regional: de Vidal de la Blache a Pierre Monbeig (1911-1957). Geousp Espaço e Tempo (Online), v. 21, n. 3, p. 793-811, dez. 2017. ISSN 2179-0892.

Disponível em: < http://www.revistas.usp.br/geousp/ article/view/134605> doi: 10.11606/issn.2179-0892. geousp.2017.134605.

\section{(c) (i) (5)}

Este artigo está licenciado sob a Creative Commons Attribution 4.0 License. 


\title{
A inserção do Brasil no sistema-Terra, na totalidade-mundo e na economia mundial, segundo a geografia regional: de Vidal de la Blache a Pierre Monbeig (1911-1957)
}

\section{Resumo}

Nesse artigo, o Brasil é visto como um espaço no qual se concebem uma visão naturalista do capitalismo e uma renovação epistemológica da geografia regional em direção a uma visão sistêmica, tendo como base as obras e os comentários de Vidal de la Blache, Albert Demangeon e Pierre Monbeig sobre o "país novo". $\bigcirc$ território é visto como inserido num sistema-Terra, numa totalidade-mundo e numa economia mundial. A partir desses conceitos, propomos uma reflexão sobre como uma visão naturalista ou uma geo-história do capitalismo tardio pode ajudar a pensar os caminhos do desenvolvimento do país.

Palavras-chave: Brasil. Visão naturalista do capitalismo. Visão sistêmica. Desenvolvimento. Geo-história.

Brazil's insertion in the Earth-system, in the totalityworld, and in international economy according to Regional Geography: from Vidal de la Blache to Pierre Monbeig (1911-1957)

\begin{abstract}
In this article, Brazil is seen as a space in which a naturalistic view of capitalism is conceived and regional geography is renewed towards a systemic view, as per Vidal de la Blache's, Albert Demangeon's, and Pierre Monbeig's works on the "new country". The country is seen as inserted in an "Earth-system", in a "totality-world", and in an "international economy". From these conceptions, we propose a reflection on how a naturalistic view or a geo-history of late capitalism can help consider how the country has developed.
\end{abstract}

Keywords: Brazil. Naturalistic view on capitalism. Systemic view. Development. Geo-history. 
No começo do século XX, a geografia regional francesa está em face aos problemas da mundialização segundo alguns especialistas (Arrault, 2007). Esse contexto é igualmente marcado por um esforço conjugado dos intelectuais e das redes diplomáticas para expandir as áreas de influência de seus tipos de racionalidade científica (Suppo, 2002). Os líderes dessa geografia traçam redes e estratégias para legitimar novos temas e lugares e, pari passu, alçarem-se como legítimos detentores dos novos discursos. A inserção do Brasil nas redes da geografia universal, desde a concepção de gêneros de vida tropicais, formulada por Vidal de la Blache, até a aparição de uma visão naturalista da instalação do capitalismo no Brasil - e sua inserção na "economia mundial" - concebida por Pierre Monbeig, faz parte desse contexto.

O encontro da geografia regional francesa com o Brasil não se deu sem que se tenha produzido um jogo de adaptações em ambos os sentidos (Lira, 2017). A geografia regional francesa modificou o Brasil, mas o Brasil também modificou a geografia regional francesa. A questão que subjaz neste movimento científico é entender como essas trocas científicas integraram dois lados do Atlântico que viviam ritmos tão descompassados. No início do século XX, enquanto o Brasil ainda vivia as cicatrizes pós-abolição da escravatura (Machado, 2012), a Europa presenciava a febre das estradas de ferro (Clozier, 1963).

No seio da conhecida linha de continuidade de Vidal de la Blache e seus discípulos, até que um discípulo indireto, Pierre Monbeig, desembarque no Brasil, o que ocorreu? Ao contrário de leituras não menos fundamentadas, que se sustentam sob outras perspectivas metodológicas (cf. Santos, C., 2016), diríamos que a continuidade predominou sobre a ruptura. $O$ porquê desta constatação é o que cabe responder ao longo deste artigo, bem como apresentar os resultados investigativos no âmbito da geografia regional, quanto à inserção do Brasil nessa geografia universal. Inserção num sistema-Terra, numa totalidade-mundo e numa economia mundial.

Na França, Pierre Monbeig foi aluno de Albert Demangeon, que, por sua vez, desenvolvera uma tese sob a orientação de Vidal de la Blache. Entre as muitas contribuições de la Blache ao edifício de uma epistemologia da geografia do mundo latino, quatro grandes concepções tiveram efeitos no Brasil: a ideia de adaptação, expansão e resistência dos gêneros de vida tropicais; a concepção de uma geo-história das civilizações que "culminava" um mundo onde o Brasil compunha os confins da história latina das civilizações (Lira, 2013); o enquadramento deste mundo por um princípio da unidade da terra; e a relatividade do fenômeno regional em que cada território se insere em totalidade-mundo por uma situação e graus de inserção específicos.

Essa herança não prescindiu de passar por processos de adaptação. Em contexto de "mundialização", após a Primeira Guerra, Albert Demangeon atualizara a contribuição de Vidal de la Blache. Por fim, Pierre Monbeig, incorporando a ideia de inserção do Brasil na economia mundial desde fins do século XIX, período que circunscreve sua tese Pionniers et planteurs de São Paulo (1952), descortina a situação geográfica específica do Brasil nesta economia, após a apropriação pelas forças do mercado mundial das fragilidades dos gêneros de vida tropicais, desembocando na elaboração de uma geo-história de um capitalismo tardio e expansivo. Essa geo-história culminou em uma visão naturalista da instalação do capitalismo no Brasil. Mon- 
beig não consolida uma ruptura com a epistemologia vidaliana, mas concebe uma inversão: a colonização do Brasil se dava predominantemente pelas forças do capital, com as mentalidades que viajaram associadas aos impulsos econômicos, mas não abole os gêneros de vida, e, ao contrário, aproveitam-se de seu atraso relativo.

As concepções metodológicas utilizadas neste trabalho embasam a compreensão de como se constituiu o método geográfico francês no seu movimento de deslocamento entre a Europa e o Brasil, de fins do século XIX à primeira metade do século XX. Pode-se situar a produção intelectual da geografia num movimento de circulação dos saberes, ou, em outras palavras, numa geografia da ciência (Livingstone, 2005).

\section{Raízes intelectuais da obra de Pierre Monbeig: os gêneros de vida tropi- cais associados à história do sistema-Terra}

A ideia de gênero de vida vincula-se não apenas à história da adaptação dos homens ao solo, como à expansão do gênero humano. O gênero de vida é um conceito de viés "biocultural" em que características elementares, no domínio da produção e da cultura, como técnicas, hábitos, habitat, vestimentas, cristalizam-se como aspectos seletivos dos agrupamentos humanos, e está ligado à própria evolução do sistema-Terra. Tais são os gêneros de vida básicos: caçadores, coletores, pescadores, pastores, nômades, agricultores. Eles haviam se constituído em estados mais puros em momentos bastante recônditos da colonização humana sobre a Terra.

gênero de vida tem um enorme efeito na formação de densidade (James, 1950), que, por sua vez, implica uma força direta na luta do homem para dominar a natureza. A partir do acréscimo de densidade, constituem-se agrupamentos humanos cada vez mais complexos, com ocupações profissionalizadas, como os burocratas, os escribas e os soldados (Diamond, 2011). Conforme o meio leve a uma especialização segundo essas formas de vida, a densidade pode mudar completamente (James, 1950).

A evolução dos gêneros de vida depende de três fatores essenciais: a disponibilidade do ambiente, a distância de outros gêneros de vida menos evoluídos dos mais avançados e o contato e a comunicação interna das regiões. Assim, em primeiro lugar, a consolidação de um gênero de vida depende da disponibilidade primária de plantas, animais e das condições ambientais, como disponibilidade de água, pedras etc. (Diamond, 2011). Em função dessa disponibilidade, desenvolve-se uma forte marca evolutiva: os caçadores e coletores representam uma adaptação primária com possibilidades limitadas, permitem uma densidade menor que a dos nômades, que por sua vez permitem uma densidade menor que os pastores e agricultores, que se desenvolvem quando as condições de produção de energia, a partir das plantas, são mais favorecidas. Além disso, a evolução do gênero de vida depende não só da disponibilidade ambiental, como também da evolução e difusão da técnica. Toda população tem potencial ao progresso, mas partem de condições ambientais e possibilidades de comunicação diferentes. A mais importante transição que marca o nascimento do mundo moderno é a transição de gêneros de vida caçadores e coletores para os gêneros de vida de pastores e agricultores, sendo os nômades uma espécie de transição (Diamond, 2011). 
Assim, a distância em relação a gêneros de vida mais avançados é também fundamental para evolução porque grande parte da adoção de nova tecnologia se dá muito mais por empréstimo do que por nascimento independente (Diamond, 2011). Ou seja, pelo raciocínio de Vidal, a questão da disponibilidade é tão fundamental quanto a dos empréstimos a certa distância.

\section{Figura 1 - Centros de origem de produção de alimentos*}

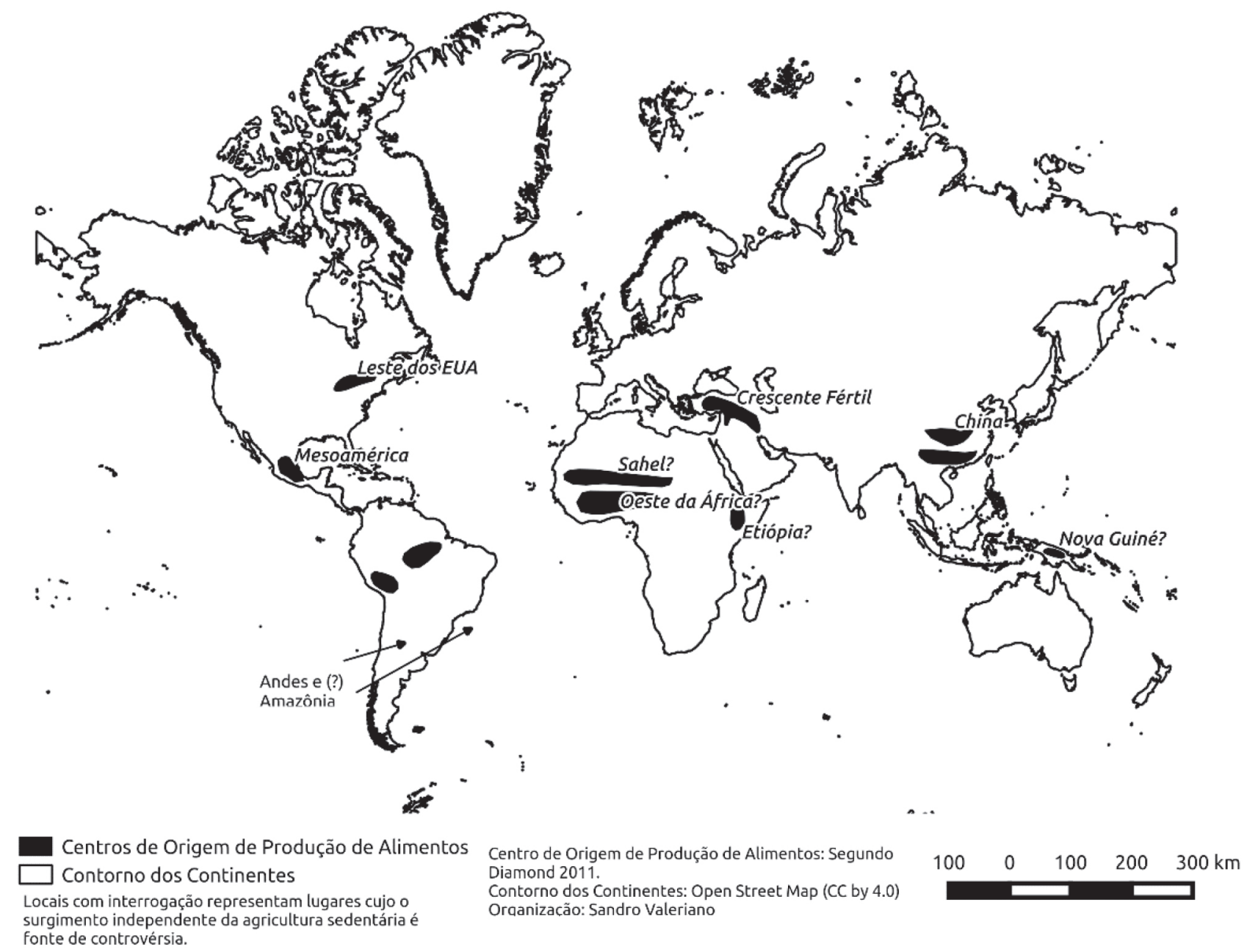

fonte: Diamond (2011).

* Os pontos de interrogação indicam lugares onde o surgimento independente da agricultura sedentária é controverso.

A maioria dos lugares em que a agricultura se implementou ocorreu por difusão. A América do Sul é, a partir do ponto de origem de sedentarização da agricultura na África e no Oriente Médio, o continente mais distante que a civilização agrícola alcançou a partir dos pontos de origem. Além disso, até o estágio de ocupação do homem na Terra que Vidal chegou a conhecer, o gênero de vida tropical era, em suas palavras, "o exemplo mais marcante de associação fechada, defendendo-se pela solidez de sua organização, apesar dos ataques múltiplos dos quais, não mais do que outras, ela não escapou" (Vidal de la Blache, 2012, p. 135). Assim, além do atraso relativo e da disponibilidade deficitária de plantas e animais domesticáveis (Diamond, 2011), há que levar em conta as vias de contato relativamente fechadas. 
Figura 2 - Como os homens se espalharam pelo mundo

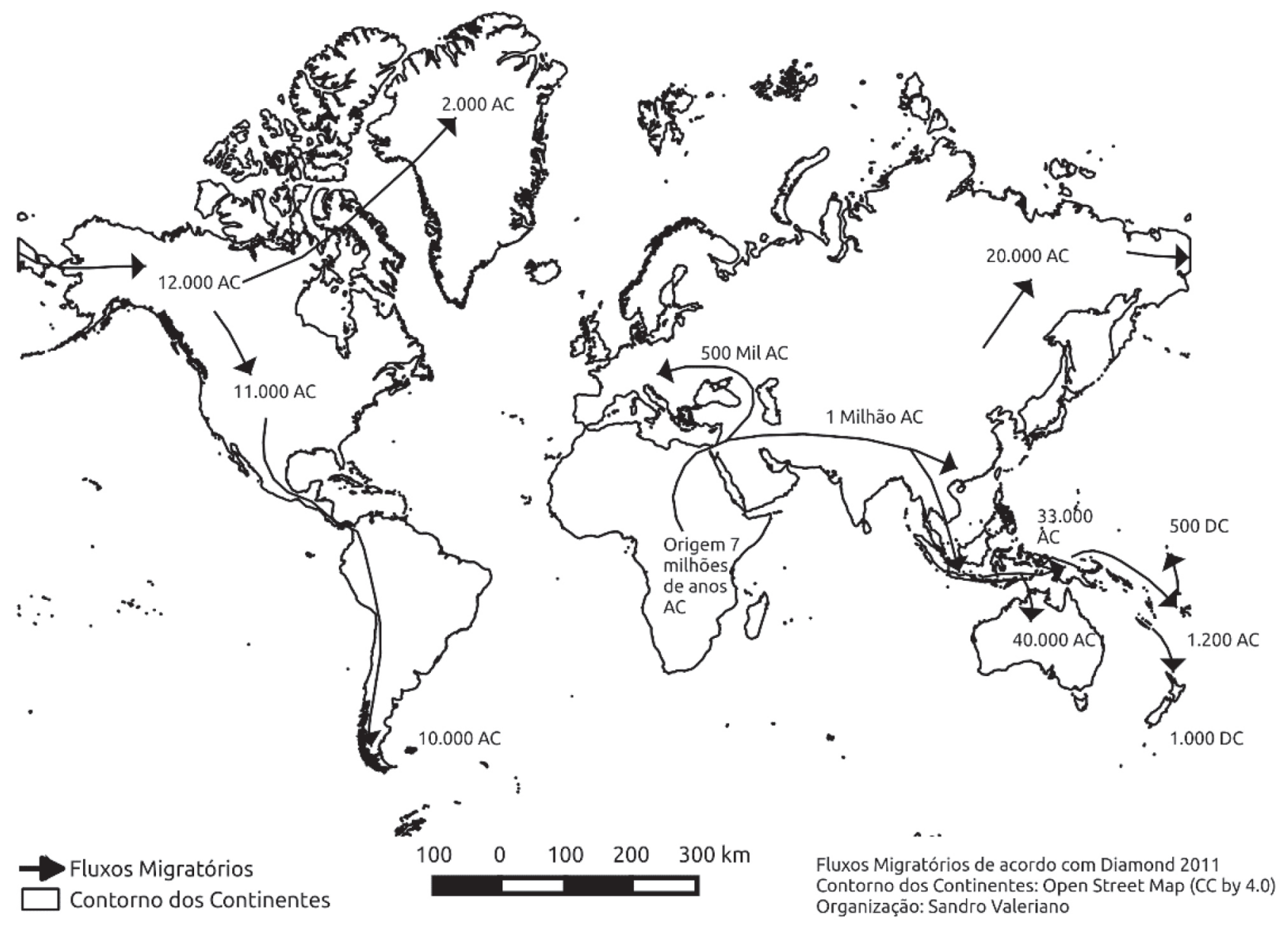

fonte: Diamond (2011).

Além da distância, uma "associação fechada" determinou um importante atraso relativo, o que pouco tem a ver com a capacidade dos indígenas de conhecer ou dominar seu meio, mas, sobretudo, de lidar com desvantagens iniciais. Além disso, a dificuldade que o meio impõe também se dá em termos de disponibilidade ambiental e agrícola. $\bigcirc$ fato de o Brasil ter paisagens de grande extensão atrapalhou os contatos, bem como uma estrutura hidrográfica predominante exorreica:

Hoje já superamos certas ilusões a propósito da fertilidade dos solos tropicais. Sabe-se que nas superfícies propícias aos cultivos são aí relativamente restritas. No Brasil, como na África, enquanto há dorsos de planaltos recobertos por silte vermelho, constituindo solos férteis, onde geralmente se concentram aldeias, há também extensões de areais graníticas, areais ferruginosas e argilas lateríticas que não permitem a atividade agrícola. A lavagem intensa e repetida a que está submetido o solo pelas chuvas tropicais tira dele substâncias fertilizantes, de modo que o esgotamento rápido é a pedra no caminho da agricultura tropical (Vidal de la Blache, 2012, p. 142-143).

Todo o trabalho de Vidal está ancorado em uma análise nos vetores de: evolução, disponibilidade, distância, expansão e empréstimos, da circulação interna do meio. Isto posto, o Brasil deve ser entendido dentro de uma larga história do sistema-Terra. 
Para Pierre Monbeig, o gênero de vida que predomina no Brasil antes da chegada dos europeus é de uma agricultura nômade. Não sendo de caçadores e coletores (como na Nova Guiné) nem de agricultores sedentários e pastores (como na Europa), não se encontra, assim, nem mais baixo estágio civilizacional, nem no mais alto. $\bigcirc$ atraso relativo dos gêneros de vida brasileiros se atribuiu à distância dos centros originários, à dificuldade de adaptação ao solo e à ausência relativa de meios de comunicação naturais. Isso não condena o Brasil a um estágio de atraso irremediável, pois dependeria do tempo de adaptação que os povos teriam para se desenvolver. Mas, repentinamente, a chegada dos europeus insere o Brasil em novas temporalidades e é aí que se funda seu atraso relativo, aparecendo também uma descontinuidade técnica entre os dois lados do Atlântico que marcará a história de sua subjugação.

\section{Vidal de la Blache e a geo-história das civilizações}

No fim do século XIX, quando o Brasil começa a ingressar no sistema econômico mundial como país independente, Pierre Monbeig gostava de enfatizar que este não era um país sem história, mesmo sendo um "país novo". Para Monbeig, admitir que o Brasil se inseria em mais uma das culminâncias de uma história global, podia ser verificado empiricamente, pela dieta meio oriental, meio americana dos indígenas, pelo estágio dos gêneros de vida, bem como pelas máquinas dos fazendeiros. Similarmente, era um pressuposto de método da geografia vidaliana.

Vidal de la Blache fora um historiador de formação. Fazer a distinção de método entre a história e a geografia tornou-se sua preocupação, não sem ressaltar as coincidências. No artigo Sur l'esprit géographique (1914) o então geógrafo afirma que a "nova geografia", longe de significar um distanciamento da história, prediz novas "perspectivas de tempo": "É preciso também tomar uma certa distância do passado, acostumar-se com outras perspectivas de tempo. $\bigcirc$ relógio do geógrafo não é exatamente o mesmo que o do historiador" (Vidal de la Blache, 1914, p. 557). Abre-se a via para uma nova concepção de tempo, para um "tempo geográfico".

A geografia francesa nasce da reformulação da concepção de tempo (Lira, 2014). 0 que define a disciplina para la Blache é que o espaço oferece ao geógrafo uma outra régua do tempo, uma nova filosofia da história. Uma história em que os personagens principais são os espaços e os homens em associação. $\bigcirc$ que articula essa filosofia no seu eixo principal não é mais a evolução dos homens, mas dos homens associados à evolução dos espaços e das técnicas. A ideia de um tempo geográfico de Vidal de la Blache organiza-se em torno de algumas noções centrais: novos fatos (fatos geográficos) e novos personagens (os lugares) ressurgem para uma nova concepção de tempo; os processos históricos são premidos por temporalidades, avanços e recuos; os espaços evoluem junto com as técnicas, por fim, que existem ondas colonizadoras que se acumulam nos espaços como que por camadas de tempo (Lira, 2014).

Trata-se de uma geo-história porque rearticula de maneira indissociável geografia e história, e porque pretende explicar a história das civilizações a partir dos espaços, além de ser uma história da adaptação e expansão no meio terrestre. Vê-se então que Vidal de la Blache concebe uma noção de tempo cuja evolução é intensiva e extensiva. Intensiva porque o homem evolui arraigado ao solo. Extensiva porque o homem também se expande. Vidal concebe uma geografia histórica, a geo-história, em que o vetor "evolução" deve ser conjugado com os 
vetores "circulação", "expansão" e "colonização" no espaço. Um raciocínio ao passo histórico, ao passo naturalista (Lira, 2013). O cerne do raciocínio geo-histórico é uma evolução que tem um desequilibrio interno estrutural que leva os sistemas biológicos e sociais à expansão. $\bigcirc$ sistema deve avançar em fronteiras e hinterlands, e aqui começa a se compreender a entrada do Brasil, ou de um pays neufs, no interior do sistema-Terra e no interior de história civilizacional. Brasil é uma área de expansão da civilização ocidental.

\section{Vidal de la Blache, a inserção dos espaços numa totalidade-mundo e a noção de circulação}

Se a geo-história é uma história espacial da evolução e expansão das civilizações. Tanto a noção de geo-história quanto a noção de circulação nos conduzem para uma metafísica do pensamento de Vidal de la Blache, conformando uma visão da natureza do mundo. Fazendo menção às ideias do geógrafo alemão Carl Ritter, ele advoga a importância da circulação para o Princípio da Unidade da Terra:

É também o velho mestre [Carl Ritter] a quem se atribuiu o mérito de lançar luz sobre a idéia de posição; através do termo Weltstellung, que ele emprega frequentemente, fica subentendida a ideia de uma humanidade em marcha [humanité en marche]. A posição é vista em relação às migrações dos povos, e é como uma espécie de instinto que aparece como uma eterna inquietude, esse Trieb que coloca em movimento, por direções determinadas pela geografia, as massas humanas (Vidal de la Blache, 1993, p. 233).

Apropriando-se das palavras de Ritter, ele declara que tudo está unido e em movimento. A física da mobilidade age de tal maneira que se podem ver na expansão dos seres verdadeiras associações entre o mundo orgânico e o inorgânico, com vistas a incrementar o movimento. A ideia de associação pode ter-se originado nos estudos de cunho naturalista de Vidal de la Blache. No artigo Les genres de vie dans la géographie humaine essa concepção de associação é transparente, bem como no artigo Des caractères distinctifs de la géographie (1913): "É assim que vemos um rio, os redemoinhos, os turbilhões e os movimentos se entrecruzarem em diversos sentidos e se combinarem com a corrente que põe em movimento a massa (Vidal de la Blache, 2006, p. 123, grifos nossos). Por exemplo, consoante Vidal, os ventos efésios no Mediterrâneo, que sopram de norte para sul "fizeram da bacia oriental uma unidade que foi conhecida já por Homero" (Vidal de la Blache, [s.d.], p. 336). Outra edificante associação entre os homens e as massas de ar abriu caminho para as explorações do Novo Mundo: o Gulf Stream (Vidal de la Blache, 1873). É comum se afirmar que a geografia regional lida com a temporalidade do que é fixo. Contudo, o movimento e a circulação são essenciais no pensamento de la Blache.

Se, para Vidal, o movimento rege a dinâmica do globo, toda a terra está sob o impulso das correntes. Logo, as regiões que se desenham se distinguem umas das outras pelo tipo de circulação que se dá no interior de cada qual. Chamamos esses "tipos" de "espacialidades da circulação" (Lira, 2013). A circulação define a situação e a distância, mas também o grau de coesão interna de cada região. Essas espacialidades na obra de Vidal são: uma tendência ao 
isolamento ou a disseminação; um modo ou processo como se dão as comunicações (relações travadas por contiguidade [proximidade] ou por redes); um ritmo de vencimento das distâncias (e, portanto, um meio de transporte característico e uma associação com os elementos do meio que lhe imprimem dinamismo, como os animais, os rios e as correntes). Além disso, é evidente a consideração de que os meios de transporte determinam dimensões escalares. Também em Vidal, diferentes meios de transporte determinam dimensões regionais.

\section{Figura 3 e 4 - $O$ império inglês* e os principais eixos dos continentes}
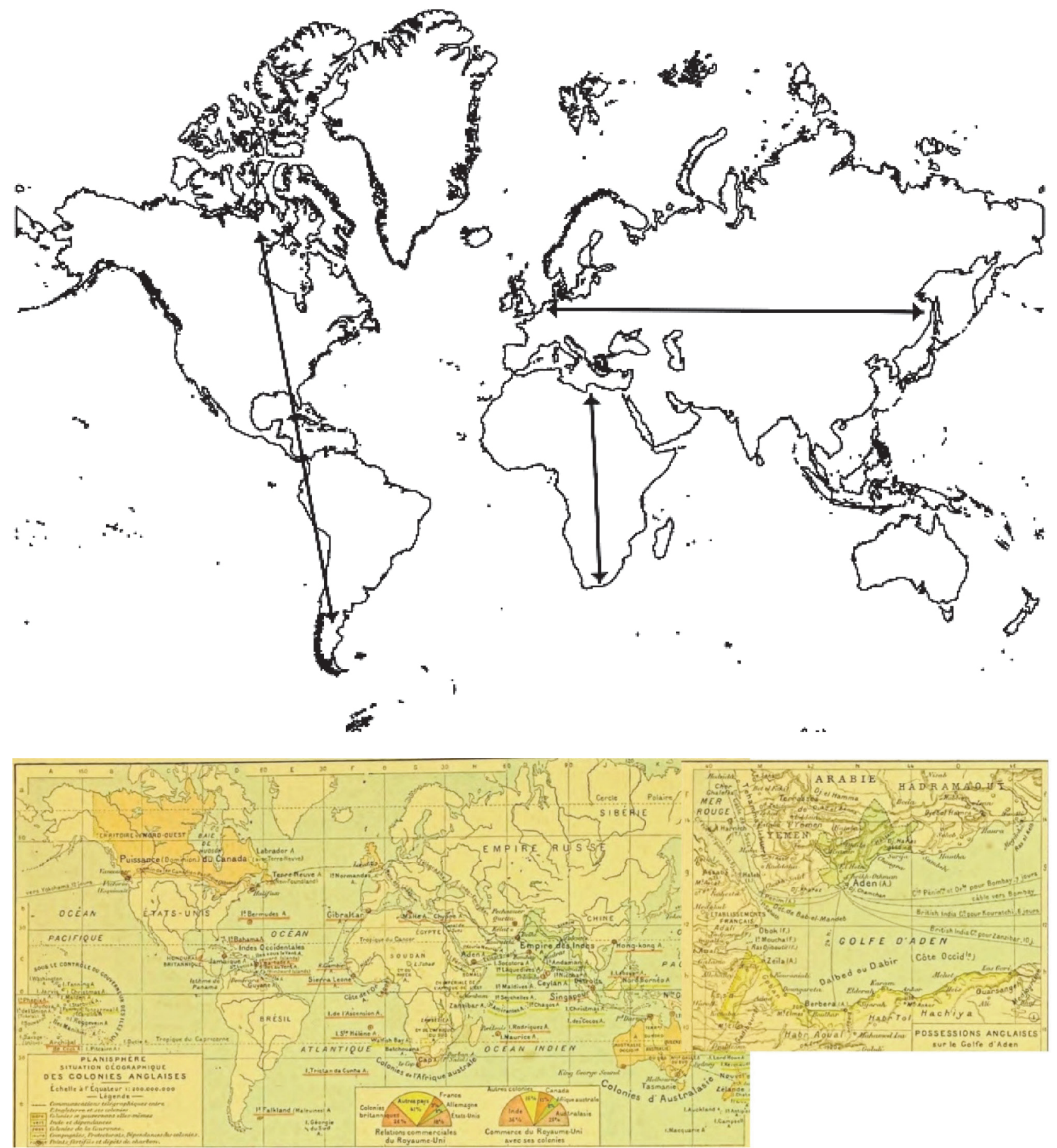

fontes: Adaptada de Vidal de La Blache (1897) e Diamond (2011), respectivamente.

* No mapa de Vidal, as correntes de trocas se dão preferencialmente no sentido dos eixos continentais. No caso da América meridional, há um desvio para o sul. 
Brasil é um país nos confins da totalidade-mundo (Figura 4). Já vimos que as rotas ambientais situam o Brasil nos seus confins. Sua extensão norte-sul, contra o gradiente climático, impõe um ritmo lento de difusão das espécies (Diamond, 2011). Sua drenagem exorreica dificulta a comunicação interna que levaria a uma evolução dos gêneros de vida. Também do ponto de vista civilizacional isso se verifica em fins do século XIX. Talvez não seja à toa que ainda nessa época o Brasil era visto pelos franceses como um Eldorado (Carneiro, 2013) e que a carta do Brasil do Atlas Vidal-Lablache seja a última das cartas no publicado em 1897.

As rotas terrestres, cujo centro no século XIX é o império inglês, são preferenciais na direção leste-oeste do grande continente eurasiano. Isso foi facilitado também pelo gradiente de mudança climática branda em sentido latitudinal (Diamond, 2011) (Figura 4). Já as rotas marítimas preferenciais se dão no Pacífico, também na direção leste-oeste, ligando Ocidente e Oriente. As rotas que atingem a América Latina, são mais pontos de parada, desvios, e entrepostos do que trocas equilibradas e constantes. $\bigcirc$ Brasil está situado nos confins das rotas ambientais e civilizacionais, nos confins da totalidade-mundo, o que contribuiu para que as trocas, que levariam à evolução dos gêneros de vida, mantivessem o país em rimo lento de evolução, ligado aos quadros de sua tropicalidade.

\section{A regionalização segundo as diferentes lógicas da evolução dos gêneros de vida e dos fenômenos econômicos}

À margem da totalidade-mundo, o Brasil começa a se inserir, desde as grandes descobertas, numa economia-mundo que gradativamente vai se tornar uma economia mundial. A questão da inserção do Brasil na economia Atlântica está inserida no problema da regionalização em geografia e das diferentes lógicas do sistema-Terra e da economia. Segundo o artigo Sur la relativité des divisions régionales (Vidal de la Blache, 1911), de, há dois processos distintos de formação das regiões. $\bigcirc$ primeiro é a disseminação por contiguidade/proximidade, que avança como uma mancha de óleo. $\bigcirc$ segundo é a disseminação por linhas de contatos, organizadas em redes. Nas formações que se espraiam viscosamente, ou seja, na disseminação por contiguidade/proximidade, os obstáculos do isolamento ainda imperam, de sorte que as trocas são mínimas e a curta distância: "A repartição das cidades obedece a uma espécie de ritmo regido pelas comodidades da circulação; corresponde mais ou menos às distâncias que são possíveis de superar pelos meios de então, para ir e para voltar, em um dia" (Vidal de la Blache, 1911, p. 4). Se o isolamento é a marca desse tipo de processo de formação das regiões, logo, a formação por contiguidade é a mais rudimentar das trocas entres os núcleos geográficos. Mas já esse tipo de contato (que prescinde das redes) não se dá dentro de regiões naturais, muito ao contrário, eles são estimulados pelas diferenças de recursos entre elas.

A troca, antes de tudo, se estabelece pelo contato com regiões vizinhas e contiguas; ela encontra seu alimento nas diferenças que as distinguem [entre as regiões]. $O$ princípio do agrupamento não é mais fundado na ideia de homogeneidade regional, mas sob a solidariedade entre regiões diversas. É uma combinação, e, por isso, um progresso (Vidal de la Blache, 1911, p. 3). 
O contato intenso abre um novo ciclo de fenômenos geográficos, em que romarias mais vastas criam novas necessidades de circulação. A circulação crescente faz nascer a necessidade de estradas, de mercados permanentes, de lugares de depósito, criações que se imprimem no solo e que fixam as correntes de circulação (Vidal de la Blache, 1911, p. 3). O movimento de saída do isolamento é o próprio movimento de ingresso na história e no mundo civilizado. Assim, além da formação das regiões por contiguidade, há uma segunda maneira de se construírem os contatos: a formação de regiões por redes. Para Vidal, as cidades, que representam uma nova ordem geográfica, são fruto das comunicações e dos transporte: "Se procurarmos quais são os princípios motores desenvolvimento das cidades e dos Estados, é necessário olhar sobretudo as mudanças que surgem dos modos de comunicação e de transporte" (Vidal de la Blache, 1898, p. 109). Essas regiões são organizadas em redes que percorrem grandes distâncias, têm relativa emancipação do meio geográfico, visto o poder da circulação rápida, distante e em grande escala, capaz de reunir elementos dispersos e independentes da condição do sítio (como a força de trabalho e as matérias-primas). A cidade é relativamente independente do meio geográfico justamente pela alta capacidade de circulação. Ela faz convergir pelas redes elementos novos e estranhos ao sítio.

Porém, essas duas maneiras de compreender o fenômeno regional, a partir de um vetor evolutivo ligado ao solo/expansão por proximidade, e um vetor espacial/ligado às redes, será atualizada quando Albert Demangeon, um discípulo de Vidal de la Blache e professor de Pierre Monbeig na Sorbonne, lançar-se na compreensão da regionalização a partir de uma importante pista de Vidal de la Blache. La Blache já havia compreendido as diferentes implicações de dois sistemas causais de formações regionais, um em face do isolamento, de um lado, e da modernização e das redes, de outro: "Ele insistia sobre a descontinuidade entre o princípio local, ligado ao solo, e o princípio da dependência horizontal, que governa a troca econômica e a organização política" (Ozouf-Marignier; Robic, 1995, p. 4).

O homem que está ligado ao gênero de vida, estabelece relações diretas de determinação, simples ou múltiplas, entre sua cultura e o solo. $\bigcirc$ homem que se incorpora à modernização é um tipo que tem função econômica, está inserido no processo de mundialização, suas relações geográficas de descolam da determinação do meio, são cíclicas e com maior poder de atuação. No âmbito econômico, não há o gênero de vida em estado puro, mas funções econômicas que os homens adquirem. Porém Vidal ainda as explicita como lógicas opostas, não fica claro como estas se associam no conjunto da Terra. Mas é por essa pista que começa a se conceber a entrada da epistemologia da geografia nos jogos do mercado. Temos, de um lado, uma epistemologia naturalista, que concebe gêneros de vida em evolução, expansão e adaptação do meio, de outro lado, temos uma geografia econômica, em que os homens são conectados por redes urbanas e transporte. Como articular essas duas lógicas? A questão inaugura o processo de adaptação dessa epistemologia da geografia aos jogos do mercado mundial.

\section{Demangeon, a geografia econômica, a associação e topografia dos fenô- menos naturais e dos fenômenos econômicos nas temporalidades do mer- cado mundial}

A contribuição de Albert Demangeon encerra uma vantagem importante para a compreensão de Pierre Monbeig sobre o Brasil: promove uma atualização das sugestões de Vidal de la Blache nos marcos de uma ruptura provocada pela Primeira Guerra Mundial. De que 
modo os fatores econômicos assumem centralidade na vida dos homens em pleno século XX? Esses fatores perderam sua conexão com a história natural da Terra? Essas indagações atravessam a obra de Albert Demangeon no período de 1920 a 1934. Suas análises da economia internacional vão contribuir para a obra de Monbeig no Brasil em quatro pontos principais: a premissa da unidade global, agora inserida numa economia mundial, recuperando a ideia de totalidade de Vidal de la Blache; a topografia das relações do homem com o meio e do homem como promotor de novas relações econômicas, recuperando a percepção das duas lógicas de formação regional, agora embasadas em causalidades geográficas associativas, e não opostas; e a dinâmica geográfica das crises capitalistas em relação ao conflito que se instala da temporalidade específica do mercado e das sazonalidades climáticas.

Primeiramente, utilizando um tipo de sistema geográfico aberto no âmbito dos Estados e dos mercados, Demangeon também se fia no axioma de que a unidade fundamentalmente circunscrita é o globo, agora não mais exclusivamente sob a ideia de um sistema-Terra, mas passando à constituição de uma economia mundial. Depois, do ponto de vista das novas condições econômicas mundiais, passa a considerar como as condições naturais ainda influem nas condições econômicas, concluindo pela mobilização de um tipo de raciocínio topográfico, cuja utilização é explicitada em texto que escreveu em 1927.

Com efeito, ele funda uma topografia das determinações geográficas: na base, temos uma relação estreita do homem com o meio, no topo, uma relação relativamente independente comandada por forças econômicas. "Podemos organizar as influências em três grandes grupos: (1) influências das condições naturais; (2) influências das condições sociais; (3) influência da economia agrícola" (Demangeon, 1927, p. 9, grifos nossos). Assim, ele articula as diferentes lógicas de regionalização de Vidal em um raciocínio topográfico, lembrando-nos a metáfora geológica de que a Terra se organiza em camadas. Essa topografia contribuirá para articular o paradigma natural com o paradigma econômico. Demangeon leva-nos a intuir, ideia incorporada por Monbeig, que o sistema econômico europeu é superestrutural, ou seja, instala-se em uma camada superior, e atinge o território apenas em pontos de contato.

Além de uma topografia das relações naturais e das relações econômicas, outro aspecto das análises de Demangeon que terá bastante impacto nos trabalhos futuros de Monbeig é a leitura geográfica das crises capitalistas, que são frutos de descompassos temporais com as rendas geradas pelos homens ainda ligados aos gêneros de vida e as demandas do mercado mundial.

Ao analisar a nova conjuntura imposta pela crise de 1929, Albert Demangeon afirma que a agricultura continua a exercer no âmbito da economia internacional e, portanto, do papel que as condições naturais continuam a incidir na vida dos homens: "E, no entanto, a agricultura constitui um elemento fundamental da economia geral. Sua produção representa um valor enorme, superior a muitos produtos industriais" (Demangeon, 1929, p. 98). A profundidade da conjuntura de crise vivida nos anos 1930 é em parte explicada pelo descompasso entre o rendimento da produção agrícola e o da produção industrial. Os baixos rendimentos dos camponeses abalam a divisão internacional do trabalho e promovem uma abundância sem destino de produtos manufaturados. Mesmo que a agricultura também passasse por modernizações, o nível de vida dos camponeses não acompanha o ritmo de produção industrial (Demangeon, 
1932, p. 113). Liberta dos contraintes du milieu e regida pela lógica do lucro, a economia industrial passa por um momento de superprodução (Demangeon, 1932, p. 5). A crise baseia-se no desequilibrio provocado entre a produção natural e a produção capitalista (comercial e industrial) a partir da qual alguns vastos espaços se orientam. Mas o essencial é que Demangeon repõe a importância das condições naturais como persistentes organizadoras das economias, fazendo despontar o primeiro esboço de uma concepção naturalista do capitalismo.

O capitalismo se insere no sistema-Terra por meio de um desajustamento com o ritmo sazonal, tentando anulá-lo e precisando se expandir e compensá-lo. Demangeon identifica, assim, um sistema cíclico de crises do capitalismo: para solucionar a falta de mercados, o capitalismo os cria, mas aumentando a produtividade natural de forma residual, não apenas o capitalismo evita transformar os gêneros de vida, como estes também resistem, gerando no longo prazo uma nova crise de superprodução.

Tal como pensa Demangeon, Monbeig também exprime o juízo de que a agricultura continua a ser comandada por forças naturais nos locais de origem. Mas a sede do lucro gera uma propensão de anularem os ritmos das estações. $\bigcirc$ mercado mundial anula os rirmos naturais dos mercados locais ao variar os espaços em que drena seus respectivos produtos e, assim, estimula a concorrência. Dessa forma, o mercado mundial mantém uma demanda e uma distribuição de produtos quase constante, levando os lugares a anularem seu ritmo natural pelo estímulo da concorrência global. Os mercados locais, que estão intimamente ligados a suas propensões, são levados a anular o tempo natural das suas estações, ou o tempo natural da produtividade do solo.

Assim as laranjas espanholas surgem de novembro a junho, seguidas até abril pelos envios da Palestina; a partir de março aparecem as laranjas brasileiras e sul-africanas, que duram até o outono. A chegada de ameixas se estende ao longo do ano, com um pico em outubro e novembro. Já mencionamos a vantagem que dá aos Estados Unidos a possibilidade de enviar peras para as ilhas britânicas de janeiro a dezembro; porém essas remessas se completam no período de março a setembro por aquelas da Austrália, e de julho a outubro, pelas da Bélgica e da Itália. $\bigcirc$ hemisfério norte, com a Espanha, fornece as uvas de verão, enquanto o hemisfério sul, com a África do Sul, as de inverno [...]. Assim, todos os países do mundo competem e, muitas vezes graças à habilidade de seus agricultores e à técnica leal de seus comerciantes, escapam do ritmo das estações (Monbeig, 1934, p. 95-96).

ajuste extensivo do capital, que precisará renovar sua demanda avançando sobre territórios virgens, terá que ocorrer numa periferia, e não no centro ou na semiperiferia, onde as trocas estão longamente associadas ao ritmo das estações, e os camponeses resistem a abandoná-las. Ao perceber esta nuança é que Monbeig começa a dar os primeiros passos rumo a sua futura compreensão do Brasil: o Brasil é uma área de expansão de um capitalismo que precisa se renovar para sair das crises potenciais. Mas esse processo pode levar a uma reviravolta das relações antes vistas como histórias anexas aos centros de dispersão do sistema-Terra e da história global? 


\section{O Brasil de Pierre Monbeig: um país tropical}

No Brasil da década de 1940, Monbeig está em via de constatar que os gêneros de vida no Brasil não são miseráveis, mas são bastante pobres, não sendo eles, portanto, o fator principal da colonização do território no século XX, devido ao descompasso do encontro com as formas modernas de colonização. No Brasil sertanejo, de leste a oeste, as condições de vida são bastante precárias, e sua base é a própria tropicalidade (Monbeig, 1984, p. 331). Já a modernização econômica é impulsionada por fatores superestruturais (como é a dimensão econômica no raciocínio da geografia regional elaborado por Albert Demangeon) mas são essas as condições superestruturais que são preponderantes na colonização do espaço, após anos de colonização portuguesa.

E rapidamente Monbeig faz a associação entre o estado sanitário do meio físico e os homens que se tornarão força de trabalho, o que equivale a dizer que, antes de se iniciar a colonização moderna, estão dadas as condições de maior exploração a que essa camada superior submete a mão de obra, aproveitando-se do atraso relativo da adaptação dos gêneros de vida e, ao tentar anular a produção em ritmo natural, não é capaz de desenvolver o território. Afinal, por diversas passagens Pierre Monbeig associa o gênero de vida e a massa de trabalhadores. Se as doenças são mazelas do gênero de vida, sob o império da tropicalidade, a permanência desse estado de coisas só pode ser explicada pelo excesso de exploração da mão de obra: "atribui-se ao meio a responsabilidade pelo miserável estado sanitário; mas a permanência de tal situação não lhe pode ser imputada" (Monbeig, 1984, p. 335). Além disso, um povoamento rarefeito sob o império de um continente tropical com pouca conexão interna resultou em uma densidade demográfica no geral bastante baixa, principalmente na direção do sertão do país. A circunstância "fechada" da floresta tropical e dos amplos espaços vazios ressaltados por Vidal de la Blache, merece ser lembrada aqui. Só não há escassez de mão de obra porque o capitalismo brasileiro quando necessitou, importou-a, mantendo elástica a oferta (Leff, 1991).

Às tais condições herdadas da tropicalidade, adiciona-se então um fator externo ao território brasileiro: os jogos do mercado mundial. É como se o Brasil, pela sua tropicalidade, partisse de um deficit que fosse preciso recuperar: o deficit da produtividade da reprodução da vida, do trabalho, da acumulação de capital sobre o território. Será preciso, assim, associar-se ao mercado mundial por causa e como remedeio deste atraso relativo, mantendo o Brasil como um país "anexo", nas palavras de Monbeig. Assim, no quesito do mercado mundial, a oscilação dos preços dos produtos primárias, como o café, se reveste de importância primordial. A colonização do planalto e do sertão no Brasil ganha impulso com a demanda do mercado mundial, e o país tem a possibilidade de buscar a recuperação do deficit, mas isso não deixa de colocá-lo em uma condição de fragilidade (Monbeig, 1984, p. 108/114). Além disso:

Nascido no momento em que se instalava a economia capitalista, o movimento de conquista dos planaltos ocidentais não cessou, pois, de progredir, a despeito das crises inerentes ao sistema e até mesmo por causa dessas crises [...]. Assim se confunde o dinamismo da frente de povoamento paulista com o da economia mundial [...]. A franja pioneira é o ponto de encontro dos apetites e ambições tanto de nacionais como de estrangeiros. $\bigcirc$ que a expõe a ser duramente atingida pelas crises, mas ao mesmo tempo lhe permite recuperar muito depressa sua vitalidade (Monbeig, 1984, p. 118-119). 
Já nessa citação, ele atribuiu ao movimento pioneiro um quarto elemento que está na base do processo de modernização: os apetites nacionais! A questão das mentalidades é essencial para Monbeig. No fundo, percebeu que as mentalidades vieram prontas em conjunto com as forças do mercado mundial. $\bigcirc$ capitalismo, no Brasil, não manipulou apenas os preços e as condições de vida, mas também as mentalidades. As mentalidades, vistas como superestruturais em certa historiografia, são no Brasil, estruturais, pois é justamente essa superestrutura europeia que viaja com mais facilidade pelo mercado do que as técnicas ou a estrutura produtiva e se instala primeiro no território. A burguesia paulista tem pressa em participar dos benefícios do luxo, da sociedade moderna. O que ele chama de "psicologia bandeirante" em sua tese é, colocada em seu contexto, uma postura bastante crítica à sede do lucro. Quando se depara com a demanda frenética do mercado mundial, e vendo terras disponíveis para aumentar a sua produtividade com baixo investimento necessário (incluído aqui a manutenção da mão de obra sem que se tenha vontade de não sanar o deficit de produtividade do meio tropical), os pequenos ou grandes capitalistas não hesitam em avançar cada vez mais, a despeito da falta de cuidados ao solo. $\bigcirc$ que significa que se dá prioridade à temporalidade do mercado em relação à temporalidade da terra, o que gera crises, como Demangeon já anunciara:

Ao mesmo tempo, essa circunstância provoca o desinteresse: se as coisas não vão bem, se a terra se fatiga, se os preços descambam, simples é o remédio, pois que basta partir para mais longe; os fartos rendimentos dos primeiros anos de cultura, num solo pela primeira vez arroteado, compensarão as fadigas, normalizando a situação. A sede de ganho rápido mantém-se continuamente desperta, por causa da facilidade de encontrar um solo virgem e altamente produtivo (Monbeig, 1984, p. 122).

Como se vê, os elementos geográficos basilares para compreensão da instabilidade da zona pioneira brasileira estão todos subordinados à questão da tropicalidade. A partir deles é que se conforma a narrativa da história da zona pioneira, um espaço e uma sociedade "em movimento". Eé essa instabilidade, esse movimento, cíclico, aliás, que Pierre Monbeig colocou no centro de sua tese. Nas hierarquias causais do raciocínio de Monbeig as bases geográficas identificadas como anteriores à modernização do território brasileiro são: tropicalidade, gêneros de vida empobrecidos, solos frágeis, vastidão espacial, fatores econômicos globais e psicologia bandeirante. Lançados os pressupostos geográficos à compreensão da instabilidade regional brasileira, Monbeig tenta compreender como são organizados esses ciclos de exploração dos homens e dos solos no capitalismo brasileiro. Termina por elaborar um raciocínio sistêmico para explicar esse capitalismo expansivo no território, ou, em outros termos, um sistema econômico cujo desequilibrio intrínseco o leva à expansão geográfica.

\section{O Brasil de Pierre Monbeig: uma geo-história do capitalismo tardio inse- rido numa economia mundial}

A geo-história do capitalismo tardio, segundo a própria sugestão de Vidal de la Blache, é uma história ao mesmo tempo evolutiva, ao mesmo tempo expansiva (no território), desenrolando-se sob condições geográficas herdadas, ou seja, as da tropicalidade. É pressuposto da 
geo-história que o Brasil esteja inserido na totalidade do sistema-Terra, numa totalidade-mundo e na economia mundial. É uma visão naturalista do capitalismo. Daí Monbeig traçar um modelo de expansão de avanço do capitalismo no Brasil que é ao mesmo tempo intensivo, ligado ao solo, e expansivo, ou seja, ligado ao avanço no território, desenvolvendo visões sistêmicas para pensar o desenvolvimento do capitalismo no Brasil, sem abandonar as determinações físicas do espaço. Ademais, o sistema de Monbeig é "aberto" e "expansivo", revelando determinações espaciais do terreno brasileiro sobre a epistemologia. O Brasil é um terreno vasto, vazio e aberto (Lira, 2017).

Quando há demanda internacional pelo café, produto primário, a cidade que é a boca do sertão na franja pioneira serve como um ponto de atração de uma mão de obra empobrecida, marcada por gêneros de vida relativamente primitivos, mediterrâneos ou sertanejos, que vêm cultivar o café. Cada vez que o ciclo econômico ou pedológico se esgota, há um movimento de êxodo da mão de obra para a cidade. Depois, renovado o ciclo da demanda internacional, o território é palco de novas mobilidades, junto com o avanço das infraestruturas para a zona pioneira e a nova boca do sertão. Inchando o mercado de trabalho, o ciclo recomeça. $\bigcirc$ ciclo de exploração do trabalhador é longo e sua condição não se eleva qualitativamente, dada a injeção crescente de mais mão de obra europeia ou sertaneja no mercado de trabalho (Leff, 1991). Esgotada a demanda, há uma nova migração para cidade, que passa por um novo ciclo de inchaço. Se a demanda se renova, novo avanço para zona pioneira.

Assim, um dos fatos que aceleram a devastação do território brasileiro é que o mercado mundial não tem hiatos sazonais, conforme já salientara Albert Demangeon, além dos apetites nacionais. Uma vez unificada a demanda global, as sazonalidades são anuladas, a demanda se renova mais depressa do que se se tratasse de uma economia nacional e os interesses não são prudentes. $\bigcirc$ Brasil e sua economia, cujo sentido é a satisfação dessa demanda mundial num ritmo veloz de acumulação do capital, que lhe falta, ingressa num ciclo frenético de exploração de seu território e devastação das florestas, intensificando os processos erosivos do solo tropical pela extrema velocidade com que o ciclo se renova. A rapidez dos processos geográficos no Brasil se explica pela sua íntima associação com o mercado mundial, visto do prisma geográfico. $\bigcirc$ tempo do Brasil é o tempo do mercado mundial. $\bigcirc$ mercado lhe impõe uma demanda frenética e a mentalidade bandeirante se associa diretamente a este frenesi. Não é uma mentalidade de desenvolvimento do território. Pode-se enriquecer em poucos anos, e os homens sabem disso. $\bigcirc$ ritmo do mundo pioneiro é o ritmo do mercado mundial:

Impôs a economia do mundo pioneiro uma técnica agrícola devastadora àqueles homens por demais apressados. Repelia tal técnica esse respeito pela terra que é próprio do camponês. Para conservar as abundantes colheitas e continuar vendendo através do mundo, os pioneiros são forçados a uma corrida ininterrupta. E por onde haviam passado os plantadores, aí renascia a erva (Monbeig, 1984, p. 389-390).

Pode-se elaborar um esquema geográfico que se afigura como uma possível leitura sistêmica da visão de Pierre Monbeig sobre o funcionamento da instabilidade regional (Figura 6) e que é uma leitura naturalista e geo-histórica da adaptação e do avanço do capitalismo no Brasil. Esse resultado epistemológico foi atingido a partir do confronto de uma tradição geográfica com o terreno brasileiro. 
Figura 5 - Modelo de funcionamento das franjas pioneiras segundo Pierre Monbeig

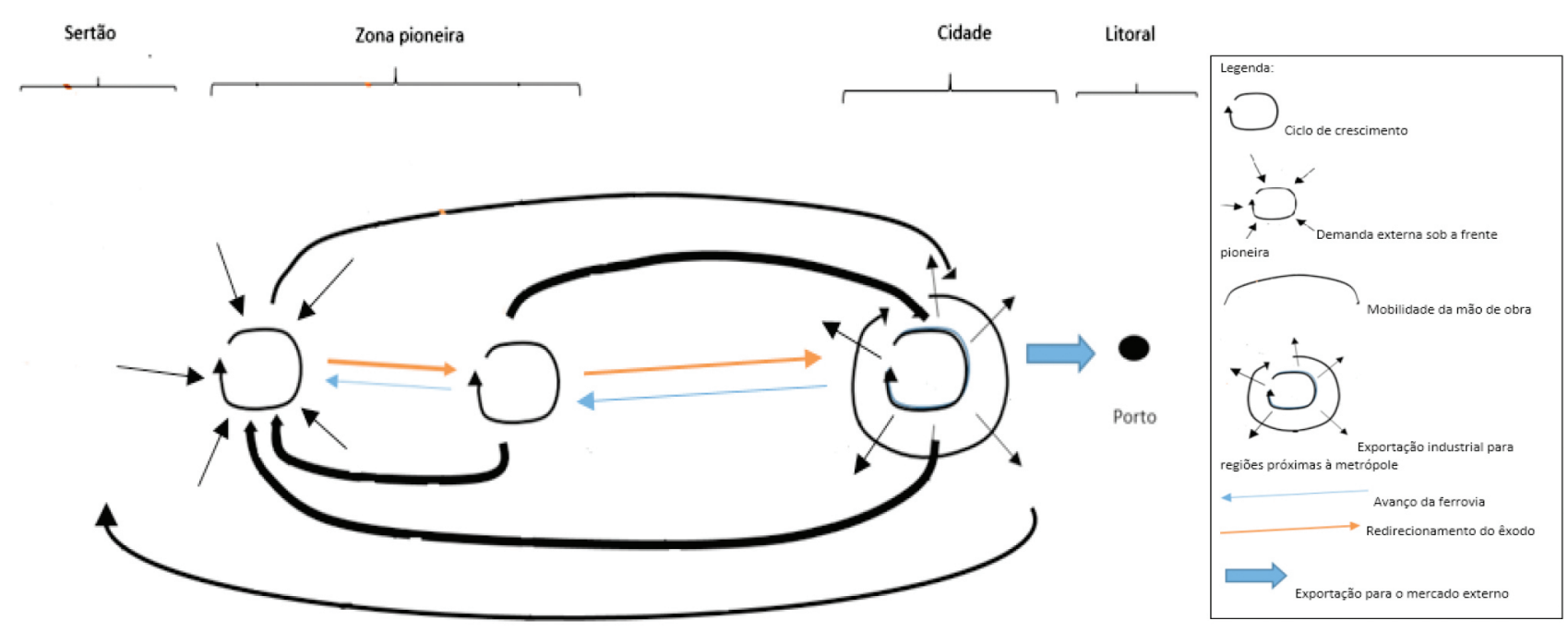

fonte: Adaptado de Lira (2017).

\section{Considerações finais}

Quando Pierre Monbeig articula fatores econômicos do Brasil inseridos na totalidade mundial e na herança dos gêneros de vida, seu raciocínio conduz a uma construção cíclica, sistêmica, aberta e expansiva do avanço do capitalismo no país. A visão sistêmica é fruto de uma visão naturalista do capitalismo em situação periférica? De acordo com Daniel Loi (1982), visões sistêmicas ainda eram raras no início da Segunda Guerra Mundial, e essa conclusão parece sugerir que a inserção do Brasil nas redes da geografia regional apontou a novidade dessas posturas sistêmicas no raciocínio de Monbeig, mesmo na geografia desenvolvida no começo do século XX. A esse respeito, temos mais um claro exemplo de como o avanço do capitalismo e das relações econômicas globais tiveram impacto na metodologia da geografia quando ela passou a incluir em suas redes explicativas a necessidade de compreender o Brasil, um país periférico onde o capitalismo se expande num sistema-mundo, numa totalidade-mundo e numa economia mundial. Nesse sentido, o Brasil também modificou a epistemologia da geografia regional.

Ao dispor diferentes lógicas em situação topográfica sobrepondo a relação natural e a realidade econômica, Pierre Monbeig não foge de sua herança epistemológica, mas, ao incluir o elemento econômico, contrapondo-se à linearidade histórica, ele cria dois tipos de raciocínio que se fundem, concebendo uma visão naturalista do avanço do capitalismo a partir do Brasil. Aparentemente, o pensamento sistêmico teve de ser elaborado de um ponto de vista externo ao centro, e Pierre Monbeig antecipou esse movimento intelectual a partir do Brasil. Finalmente, por suas considerações, uma possibilidade de repensar o Brasil atualmente é, por exemplo, perguntar quais são suas possibilidades de desenvolvimento sob a ótica da geo-história ou de uma visão naturalista do capitalismo. Nesse sentido, investir no território tornando-o produtivo e melhorando a comunicação interna - e também sua posição num tabuleiro global - em termos de distâncias relativas e trocas são algumas das peças-chave para compreender as possibilidades de desenvolvimento de um país. Nesse sentido, poder-se-ia conceber um plano de desenvolvimento mais detalhado a partir de um paradigma naturalista. 


\section{Referências}

ARRAULT, J.-B. Penser à l'échelle du Monde: histoire conceptuelle de la mondialisation en géographie (fin du XIXe siècle/entre-deux-guerres). Tese (Doutorado) - Université Paris 1 - Panthéon Sorbonne, Paris, 2007.

BERDOULAY, V. La formation de l'école française de géographie (1870-1914). Paris: Bibliothèque Nationale, 1984.

- La métaphore organiciste: contribution à l'étude du langage des géographes. Annales de Géographie, Paris, v. 91, n. 507, p. 573-586, 1982.

CARNEIRO, J. P. J. A. O último propagandista do império. $\bigcirc$ "barão" de Santa-Anna Nery (1848-1901) e a divulgação do Brasil na Europa. Tese (Doutorado em Geografia Humana) - Faculdade de Filosofia, Letras e Ciências Humanas, Universidade de São Paulo, São Paulo, 2013.

CLOZIER, R. Géographie de la circulation. Paris: Génin, 1963.

DEMANGEON, A. Aspects nouveaux de l'économie internationale. Annales de Géographie, Paris, v. 41, n. 230, p. 113-130, 1932.

Les aspects actuels de l'économie internationale (Deuxième article). Annales de Géographie, Paris, v. 38, n. 212, p. 97-112,1929.

. La géographie de l'habitat rural [premier article]. Annales de Géographie, Paris, v. 36, n. 199, p. 1-23, 1927.

DENIS, P. Amérique du Sud. Paris: Armand Colin, 1927. (Collection Géographie Universelle, XV).

DIAMOND, J. M. Armas, germes e aço. Rio de Janeiro, São Paulo: Record, 2011.

Guns, germs, and steel: the fates of human societies. New York: Maple-Vail, 1999. Disponível em: http://yanko.lib.ru/books/natural/diamond_jared=guns_germs_ and_steel-en-a.htm. Acesso em: 13 nov. 2017.

GRATALOUP, C. Géohistoire de la mondialisation. Paris: Armando Colin, 2010.

HOBSBAWM, E. A era dos extremos: o breve XX. São Paulo: Companhia das Letras, 1995. HOUAISS. Dicionário Eletrônico da Língua Portuguesa, 2009.

JAMES, P. E. Latin America. London/Toronto/Melbourne/Sydney/Wellington: Cassell and Company Ltd., 1950.

LEFF, N. Subdesenvolvimento e desenvolvimento no Brasil: Estrutura e mudança econômica 1822-1947. Rio de Janeiro: Expressão e Cultura, 1991. v. 1.

LIRA, L. A. Pierre Monbeig e a formação da geografia brasileira: uma ciência no contexto do capitalismo tardio. Erosão dos valores literários, "tentação à ação" e sistematização do método (1925-1957). Tese (Doutorado em Geografia Humana) - Faculdade de Filosofia, Letras e Ciências Humanas, Universidade de São Paulo, São Paulo, 2017. 
Vidal de la Blache historiador. Confins [Online], v. 21, 2014. Disponível em: http:// confins.revues.org/9636; DOI: 10.4000/confins.9636. Acesso em: 26 jun. 2017.

O Mediterrâneo de Vidal de la Blache: o primeiro esboço do método geográfico (1872-1918). São Paulo: Alameda/Fapesp, 2013.

LIVINGSTONE, D. N. Putting Science in its Place: Geographies of Scientific Knowledge. London/Chicago: The University of Chicago Press, 2004.

LOI, D. Sur les concepts de description, d'explication et de causalité dans la géographie classique française. Arquivos do laboratório EHGO, Paris 1, 1982.

MACHADO, L. O. Origens do pensamento geográfico no Brasil: meio tropical, espaços vazios e ideia de ordem (1870-1930). In: CASTRO, I. E.; GOMES, P. C. C.; CORREAA, R. L. (Org.). Geografia: conceitos e temas. Rio de Janeiro: Bertrand Brasil, 2012. p. 309-349.

MELLO, J. M. C. O capitalismo tardio. São Paulo: Brasiliense, 1991.

MONBEIG, P. Pioneiros e fazendeiros de São Paulo. São Paulo: Hucitec/Polis, $1984[1952]$.

Pionniers et planteurs de São Paulo. Paris: Armand Colin, 1952.

Les importations de fruits frais en Grande-Bretagne. Annales de Géographie, Paris, v. 34, n. 241, p. 94-96, 1934.

MORERA, E. Gramsci, materialism and philosophy. New York/London: Routledge, 2014.

OZOUF-MARIGNIER, M.-V.; ROBIC, M.-C. La France au seuil des temps nouveaux: Paul Vidal de la Blache et la régionalisation. L'Information Géographique, Paris, n. 2, p. 46-56, 1995.

SANTOS, C. S. Pierre Monbeig e o vacilo de uma tradição nos trópicos. Confins [En ligne], n. 26, 2016. Disponível em: http://confins.revues.org/10724. Acesso em: 5 jan. 2018.

SUPPO, H. R. La politique culturelle française au Brésil entre les années 19201950. Tese (Doutorado) - Université Paris III - Sorbonne Nouvelle, Paris, 2002.

VIDAL DE LA BLACHE, P. Os gêneros de vida na geografia humana [primeiro artigo]. In: HAESBAERT, R.; NUNES, S. P.; RIBEIRO, G. Vidal, vidais. Rio de Janeiro: Bertrand, 2012[1911]. p. 131-158.

. Estradas e caminhos da França antiga. GEOgraphia, Rio de Janeiro, v. VIII, n. 16, 2006[1902].

. La Géographie Humaine, ses Rapports avec la Géographie de la Vie. In: SANGUIN,

A.-L. Vidal de la Blache: un génie de la Géographie. Paris: Belin, 1993. p. 223-244.

Sur L'Esprit Géographique. Revue Politique et Littéraire (Revue Bleu), Paris, v. 52, n. $18,1914$. 
Des caractères distinctifs de la géographie. Annales de Géographie, Paris, v. 22, n. 124. p. 289-299, 1913.

Sur la relativité des divisions régionales. Athena, n. 11, 1911.

La Géographie Politique, a propôs dês Écrits de M. Frédéric Ratzel. Annales de Géographie, Paris, v. 7, n. 32, p. 97-111, 1898.

Atlas général. Paris: Armand Colin, 1897.

Péninsule Européenne: L'océan et La Méditerranée. Leçon d'ouverture du cours d'histoire et géographie a la Faculté des Lettres de Nancy. Nancy/Paris: Berger-Levrault et Librairies-Éditeurs, 1873.

Princípios de geografia humana. Lisboa: Cosmos, [s.d.]. 